\title{
A controlled trial of nandrolone decanoate in the treatment of rheumatoid arthritis in postmenopausal
} women

\author{
H A BIRD ${ }^{1}$ L BURKINSHAW ${ }^{2}$ D PEARSON ${ }^{2}$ P J ATKINSON ${ }^{3}$ \\ P A LEATHAM, ${ }^{1}$ J HILL, ${ }^{1}$ A RAVEN, ${ }^{*}$ AND V WRIGHT
}

From the 'Clinical Pharmacology Unit, Royal Bath Hospital, Harrogate and the General Infirmary at Leeds; the Departments of ${ }^{2}$ Medical Physics and ${ }^{3}$ Oral Biology, University of Leeds, Leeds

SUMMARY To determine whether an anabolic steroid had any benefit in the treatment of rheumatoid arthritis 47 patients entered a parallel group study. Twenty four received nandrolone decanoate $50 \mathrm{mg}$ intramuscularly every third week for two years and 23 patients received no anabolic steroids. Other therapy was unaltered. Patients attended for clinical and biochemical assessments as well as the objective assessments of elementary body composition by in vivo neutron activation analysis and measurement of the mineral content of the distal femur by single photon absorptiometry on five occasions. A modest clinical deterioration (except for grip strength) was seen in both groups. No significant changes in calcium or alkaline phosphatase were seen. There was no significant change in total body calcium, total body phosphorus, body weight, or bone index/bone width measurements in either group. Significant increases occurred in total body nitrogen, total body potassium, haemoglobin, and packed cell volume (by six months) in the group treated with nandrolone decanoate. Comparison of 10 patients in the group treated with nandrolone decanoate also receiving oral steroid therapy with 14 patients in this group not receiving oral steroid therapy showed no significant differences. The main side effect of nandrolone decanoate was hoarseness. No radiological changes were seen. Nandrolone decanoate, in a dose that produces a significant anabolic effect, has no demonstrable action on bone metabolism in rheumatoid arthritis but may improve the chronic anaemia by six months.

Key words: anabolic steroid, bone density.

Rheumatoid arthritis is associated with widespread tissue wasting, particularly of muscles around the involved joints, and produces a normochromic normocytic anaemia. Perhaps because of this, anabolic steroids are sometimes prescribed by rheumatologists for their more wasted patients, though we are not aware of any controlled studies that support the use of these drugs in this way.

Bone metabolism in rheumatoid arthritis is relatively underinvestigated. Osteomalacia has been reported, ${ }^{1}$ and although bone histology is frequently abnormal in patients selected because of bone pain or fractures, ${ }^{2}$ current evidence suggests that apart

Accepted for publication 14 August 1986.

Correspondence to $\mathrm{Dr} \mathrm{H}$ A Bird. Clinical Pharmacology Unit. Royal Bath Hospital, Cornwall Road, Harrogate HG1 2PS.

*Present address: DAR Ltd, Cambridge Innovation Centre. Science Park. Cambridge CB4 4GF. from mild hypercalcaemia of undetermined cause, bone metabolism as measured by serum parameters is essentially normal in most rheumatoid patients. ${ }^{3}$ We have failed to show any abnormality of serum levels of 25-hydroxyvitamin $\mathrm{D}_{3}{ }^{4}$ or of $1 \alpha, 25$-dihydroxyvitamin $\mathrm{D}_{3}{ }^{5}$ in patients with rheumatoid arthritis, though an increased bone metabolisr.. has recently been demonstrated in this disease. ${ }^{6}$ There is undoubtedly a juxta-articular osteopenia in rheumatoid arthritis, most marked around the most inflamed joints. Since anabolic steroids are frequently used in the management of osteoporosis ${ }^{7}$ and since a beneficial effect of their use in this condition can be measured by neutron activation analysis, ${ }^{89}$ it seemed appropriate to evaluate nandrolone decanoate as a typical anabolic steroid using this technique in rheumatoid arthritis. We also added single photon absorptiometry as a localised 
assessment of bone density at the distal femur. ${ }^{10}$ This method was felt to supersede earlier assessments of osteopenia in rheumatoid arthritis that used cortical thickness. ${ }^{11}$

\section{Patients and methods}

Forty seven postmenopausal female patients were recruited for the study. All patients had classical or definite rheumatoid arthritis according to the American Rheumatism Association criteria, ${ }^{12}$ and the arthritis was of at least one year's duration. Patients had to be physically able to complete the somewhat arduous neutron activation analysis assessments. Exclusion criteria were: (a) patients who had received any anabolic steroids within the previous two years; $(b)$ patients with a known sensitivity to nandrolone decanoate; $(c)$ patients taking vitamin $\mathrm{D}$ or analogues; $(d)$ patients with abnormal thyroid or parathyroid function; $(e)$ patients receiving oestrogen therapy; and $(f)$ patients who had received cytotoxic therapy within the previous year.

Patients were allocated at random to one of two groups. Those in the first group received all existing antirheumatoid arthritis therapy in constant dosage with the addition of nandrolone decanoate, $50 \mathrm{mg}$ given by intramuscular injection every three weeks for a period of two years. The second (controlled) group received all existing antirheumatoid arthritis therapy in constant dosage but had no injections of nandrolone decanoate. In view of the objective nature of the assessments, and at the insistence of the Medical Ethics Committee, placebo injections or tablets were not given. The study was thus a single blind parallel group study.

On admission to the study demographic data were recorded, including date of birth, weight, height, occupation, gynaecological history, and details of the extent of the arthritis. Recent past medication was recorded. Patients then attended a special clinic for regular assessment at $0,6,12,18$, and 24 months. At each assessment the following clinical parameters were recorded: $(a)$ grip strength-left and right grip strength were measured three times and the mean grip strength calculated; $(b)$ functional capacity scored as follows: $(i)$ completely mobile, (ii) mobile with difficulty, (iii) mobile with stick, (iv) confined to house, ( $v$ ) bedfast; (c) the average duration of morning stiffness in the week preceding the examination, recorded in minutes; $(d)$ the Ritchie articular index ${ }^{13} ;(e)$ general joint pain and bone pain, recorded by the patient using horizontal visual analogue scales $110 \mathrm{~mm}$ long, marked 'no pain' at one end 'worst possible pain' at the other, and divided into 10 equal divisions by tick marks; $(f)$ laboratory measurements, performed at each of the visits, including haemoglobin, packed cellow. volume, white blood cell count, erythrocyte sedi- $\overrightarrow{\vec{F}}$ mentation rate (ESR), latex test, and sheep cell agglutination test for rheumatoid factor, serum? protein, serum calcium, serum phosphate, serum $\frac{\bar{\sigma}}{\bar{c}}$ urea, serum aspartate transaminase, alkaline phos- $\frac{\widehat{\sigma}}{\sigma}$ phatase, serum electrolytes, urinary calcium, $\stackrel{\mathbb{}}{\circ}$ urinary phosphate, urinary hydroxyproline, and urinary creatinine. All urinary measurements were $\overrightarrow{0}$ reported as ratios to urinary creatinine.

An $x$ ray examination of the spine, hands, and $\vec{\omega}$ feet was made at 0 and 24 months. The $x$ rays were assessed in a single reporting session by a single $\frac{0}{2}$ observer (HAB), using standard masking techniques to guarantee blindness.

At each clinic visit the objective assessments of neutron activation analysis and single photon $v$ absorptiometry were performed. For neutron음 activation analysis ${ }^{9}$ the supine patient was irradiated bilaterally with a horizontal beam of $14 \mathrm{MeV} ?$ neutrons to a dose equivalent of $10 \mathrm{mSv}$. The patient $\stackrel{\text { }}{\frac{\mathrm{a}}{3}}$ was then transferred to an eight crystal whole body counter and the induced activity measured for $30 \vec{\otimes}$ minutes. The system was calibrated for nitrogen,. potassium, phosphorus, chlorine, sodium, and cal-o cium using realistic anthropomorphic phantoms which included a simulated skeleton. The best way to assess the reproducibility of the method would@ have been to measure repeatedly a number of people whose calcium content was not expected to change. This was ruled out by ethical considera- $\frac{0}{3}$ tions, and instead two anthropomorphic phantoms were each measured five times. Total body calcium had a standard deviation of $36 \mathrm{~g}$.

For single photon absorptiometry measurements of bone mass were made at the lower end of the femur using a technique of radiation absorption. analysis. Patients were seated with one leg sup-ô ported by a parallel sided Perspex trough so that the femoral shaft was in a horizontal position and theo skin in close contact with the walls of the trough. The leg was always scanned at one fifth of theo distance between the lateral epicondyle and the greater trochanter. Photon emission from a ${ }^{241} \mathrm{Amos}$ was finely collimated to a beam width of $12 \times 2 \mathrm{~mm} N$ and passed through the leg. The transmitted beam was detected by a sodium iodide scintillation crystalo scanning across the leg at a uniform speed. From the resultant trace the bone width was measured and ac bone index calculated from the area under the peak. The bone index is expressed as the mass of bone, in terms of a selected bone powder standard, per unito length of the femur. The ratio bone index/boned width was also calculated since this quantity has been shown to have better precision than bone index itself. ${ }^{14}$ The apparatus was checked each day by 
scanning an aluminium tube embedded in a block of Perspex; the coefficient of variation of the results was $\pm 2 \%$. Reproducibility of measurement of patients has been previously assessed in 17 volunteers, each on two occasions separated by intervals of one to three months. ${ }^{14}$ The standard deviation of the bone index was $0.43 \mathrm{~g} / \mathrm{cm}$, representing $5-8 \%$ of the subjects' measured values; bone index/bone width had a standard deviation of $0.08 \mathrm{~g} / \mathrm{cm}^{2}$, i.e., $3-4 \%$ of the subjects' measured values.

The power of the study to ascertain whether or not total body calcium, bone index, and bone index/bone width changed more in one group than the other was assessed, assuming initially that measurements made only at the beginning and end of the study would be analysed. The following additional assumptions were made: $(a)$ the measurements made in this study would have the same reproducibilities as those described above; $(b)$ the standard deviation of each measured change in each group would be determined by the reproducibility of the method rather than by variability in the actual changes suffered by individual patients; and $(c)$ the measured changes in each group would be normally distributed.

The calculation showed that with 24 patients in each group there would be a $90 \%$ chance of detecting, at the $5 \%$ level of significance, a difference between the mean changes of total body calcium in the two groups of $34 \mathrm{~g}$. Thus the study was very likely to detect a difference of $37 \mathrm{~g}$, as found in a similar study of a different anabolic steroid. ${ }^{8}$ The corresponding limits of detection for bone index and bone index/bone width were 0.4 $\mathrm{g} / \mathrm{cm}$ and $0.08 \mathrm{~g} / \mathrm{cm}^{2}$ respectively. We knew of no comparable study that would indicate the likely differences between the groups for these quantities. The detection limits, however, represented differences in rates of change of only a few per cent a year and were deemed acceptable.

All patients were evaluated for side effects using a standard check list on which 18 symptoms were rated as mild, moderate, or severe if present. Any other side effects reported by the patients were noted.

\section{STATISTICAL METHODS}

For all variables the two treatment groups have been compared on entry to the study, and treatment effects have been compared over the period of the study. For most of the laboratory measurements, bone density measurements, and results obtained from neutron activation analysis, parametric tests were used when making statistical comparisons. Where measurements were made on restricted scales or in other cases where the data were unlikely to be normally distributed, non-parametric methods were used.

When parametric testing was applicable for the main comparison between treatments an analysis of covariance for a repeated measures design $^{15}$ was used. In a single case, where the covariate was found to be non-significant, an analysis of variance for repeated measures was used. Where necessary, missing values were interpolated or extrapolated by linear regression. This method was thought optimal after initial inspection of the data.

For total body calcium and bone index/bone width measurements further analyses of covariance were performed to examine the possible effects of steroidal antirheumatic therapy upon these variables and the interaction between antirheumatic therapy and nandrolone decanoate treatment.

Non-parametric tests of treatment effects were made with the Mann-Whitney $U$ test ${ }^{15}$ by comparing the changes occurring between 0 and 24 months for each treatment group. Other tests used $^{1617}$ are mentioned in the 'Results' section.

\section{Results}

Demographic data for control and treatment groups are shown in Table 1. Student's $t$ test or $\chi^{2}$ test for frequency data showed no statistical differences between the two treatment groups. Thirteen patients failed to complete the two year study, five from the control group and eight from the treatment group. In the control group one patient died, two declined to continue with neutron activation analysis, and two withdrew for personal reasons. In the nandrolone

Table 1 Characteristics of patients on entry to the study

\begin{tabular}{lcc}
\hline Parameter & $\begin{array}{l}\text { Control } \\
\text { group } \\
(n=23)\end{array}$ & $\begin{array}{l}\text { Nandrolone } \\
\text { decanoate } \\
\text { group }(n=24)\end{array}$ \\
\hline Age (years) & $60 \cdot 7(1 \cdot 4)^{*}$ & $61 \cdot 6(1 \cdot 3)$ \\
Age at menarche (years) & $14 \cdot 1(0 \cdot 4)$ & $13 \cdot 5(0 \cdot 4)$ \\
Age at menopause (years) & $46 \cdot 1(1 \cdot 2)$ & $46 \cdot 6(1 \cdot 0)$ \\
Time since menopause (years) & $14 \cdot 0(1 \cdot 8)$ & $15 \cdot 4(1 \cdot 5)$ \\
Ovariectomy & $1 / 23$ & $0 / 24$ \\
Nodules present & $16 / 23$ & $9 / 24$ \\
Antirheumatic therapy: & $19 / 23$ & $22 / 24$ \\
$\quad$ NSAIDs & $11 / 23$ & $10 / 24$ \\
Corticosteroids & $6 / 23$ & $6 / 24$ \\
Gold & $4 / 23$ & $4 / 24$ \\
Others & & \\
\hline
\end{tabular}

${ }^{*}$ Figures are mean (SEM) or, where appropriate, frequencies. †NSAIDs $=$ non-steroidal anti-inflammatory drugs. 
Table 2 Clinical assessment parameters

\begin{tabular}{|c|c|c|c|c|c|c|c|}
\hline \multirow[t]{2}{*}{ Parameter } & \multirow{2}{*}{$\begin{array}{l}\text { Treatment } \\
\text { group }\end{array}$} & \multicolumn{5}{|c|}{ Assessment (month) } & \multirow{2}{*}{$\begin{array}{l}\text { Change } \\
(24-0)\end{array}$} \\
\hline & & 0 & 6 & 12 & 18 & 24 & \\
\hline \multirow[t]{2}{*}{ Grip strength $(\mathrm{mmHg})$} & $\mathrm{ND}+$ & $81 \cdot 4(9 \cdot 5) \doteqdot$ & $91.4(9.9)$ & $86 \cdot 6(6 \cdot 2)$ & $95 \cdot 1 \quad(7 \cdot 5)$ & $92.9(7.9)$ & $+11 \cdot 5(7 \cdot 7)$ \\
\hline & Control & $66 \cdot 1(6 \cdot 9)$ & $73 \cdot 6(8 \cdot 3)$ & $77.9(7 \cdot 7)$ & $79 \cdot 4(10 \cdot 2)$ & $77 \cdot 7(6 \cdot 8)$ & $+11 \cdot 6(6 \cdot 3)$ \\
\hline \multirow{2}{*}{$\begin{array}{l}\text { Morning stiffness } \\
(>15 \mathrm{~min})\end{array}$} & ND & $6 / 17$ & $6 / 17$ & $11 / 17$ & $10 / 17$ & $13 / 17$ & \\
\hline & Control & $8 / 18$ & $11 / 18$ & $12 / 18$ & $12 / 18$ & $12 / 18$ & \\
\hline \multirow[t]{2}{*}{ Articular index } & ND & $12 \cdot 2(2 \cdot 6)^{*}$ & $11 \cdot 1(2 \cdot 8)$ & $13 \cdot 7(2 \cdot 2)$ & $13 \cdot 7 \quad(3 \cdot 1)$ & $13 \cdot 4(3 \cdot 0)$ & $+1 \cdot 2(1.9)$ \\
\hline & Control & $23 \cdot 8(3 \cdot 8)$ & $21 \cdot 7(3 \cdot 4)$ & $24 \cdot 6(4 \cdot 0)$ & $26.5 \quad(3.4)$ & $25 \cdot 2(3 \cdot 5)$ & $+1 \cdot 4(2 \cdot 3)$ \\
\hline \multirow[t]{2}{*}{ Joint pain } & ND & $3.6(0 \cdot 5)$ & $2 \cdot 3(0 \cdot 4)$ & $4 \cdot 1(0 \cdot 6)$ & $4.6 \quad(0 \cdot 6)$ & $4 \cdot 8(0 \cdot 7)$ & $+1 \cdot 2(0 \cdot 7)$ \\
\hline & Control & $4 \cdot 5(0 \cdot 5)$ & $4 \cdot 1(0 \cdot 7)$ & $5 \cdot 5(0 \cdot 6)$ & $5.9 \quad(0 \cdot 7)$ & $6 \cdot 3(0 \cdot 5)$ & $+1.8(0 \cdot 7)$ \\
\hline \multirow{2}{*}{ Bone pain } & ND & $2 \cdot 5(0.7)$ & $2 \cdot 2(0 \cdot 5)$ & $3 \cdot 2(0 \cdot 6)$ & $3 \cdot 0 \quad(0 \cdot 6)$ & $2 \cdot 7(0 \cdot 5)$ & $+0 \cdot 2(0 \cdot 5)$ \\
\hline & $\begin{array}{l}\text { Control } \\
\text { ND }\end{array}$ & $4 \cdot 2(0 \cdot 6)$ & $2 \cdot 5(0 \cdot 8)$ & $4 \cdot 2(0 \cdot 8)$ & $5 \cdot 1 \quad(0 \cdot 7)$ & $4 \cdot 8(0 \cdot 8)$ & $+0.6(0.9)$ \\
\hline \multirow{8}{*}{ Functional capacity } & 1 & 6 & 8 & 8 & 7 & 8 & Sixteen \\
\hline & 2 & 8 & 6 & 6 & 7 & 5 & better or no \\
\hline & 3 & 2 & 3 & 2 & 3 & 4 & change, one \\
\hline & $\begin{array}{l}4 \\
\text { Control }\end{array}$ & 1 & 0 & 1 & 0 & () & worse \\
\hline & 1 & 4 & 4 & 3 & 3 & 1 & Thirteen \\
\hline & 2 & 9 & 9 & 7 & 9 & 10 & better or no \\
\hline & 3 & 3 & 4 & 7 & 5 & 6 & change. five \\
\hline & 4 & 2 & 1 & 1 & 1 & 1 & worse \\
\hline
\end{tabular}

*Significantly different from control $(p<0 \cdot(05)$ using the Mann-Whitney $U$ test. $\dagger \mathrm{ND}=$ nandrolone decanoate.

¥Figures are mean (SEM).

decanoate group one patient died, two patients refused regular injections, and one patient declined to continue with neutron activation analysis. Four patients withdrew because of side effects, one because of excessive weight gain and three because of hoarseness or voice changes.

Clinical assessments are shown in Table 2. At the first assessment, before the start of treatment, the patient groups were significantly different with respect to their articular index scores. Other clinical variables suggested that the control patients tended to be more severely affected by arthritis, though allocation had been by random code, and none of the other differences were statistically significant. Over the course of the study grip strength measurements showed a slight improvement in both treatment groups, but other variables suggested a slight deterioration in the patients' condition over the two year period. In no case was there a significant difference between the treatment groups when comparing the changes over 24 months.

Laboratory data are shown in Table 3 . Significant haematological changes were a rise in haemoglobin and packed cell volume on treatment (both $\mathrm{p}<0 \cdot 01)$. There was no significant change in serum

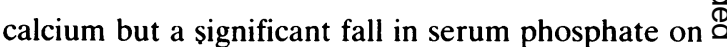
treatment $(\mathrm{p}<0 \cdot 01)$. There was no change in urinary $\overrightarrow{\overrightarrow{0}}$ calcium/creatinine or phosphate/creatinine ratios $\exists$ but a significant fall in hydroxyproline/creatinine ratio with treatment $(\mathrm{p}<0.05)$. No significant changes occurred with treatment for bone index/ bone width or for total body calcium or phosphorus or body weight, but both total body potassium $(\mathrm{p}<0.01)$ and nitrogen $(\mathrm{p}<0.01)$ increased with treatment.

When $x$ rays were read blind no improvement in bone density of the spine was seen with treatment. 을 Rheumatoid deterioration of the hands and feet $D$ continued equally in both groups. Side effects were more frequently seen in the treatment group. The $N$ principal effects were hoarseness, slight facial hair growth, and occasionally breast enlargement.

\section{Discussion}

The imbalance of baseline clinical assessments between the two groups occurred despite the strict $\stackrel{?}{?}$ allocation by a random code and probably reflects $T$ the relatively small number of patients recruited to the study. Nevertheless; a study of this magnitude $\stackrel{\square}{\square}$ stretched the full resources of the large rheuma- $\mathbb{Q}$ tology clinic over a two year period and it was not? 
Table 3 Laboratory assessment parameters

\begin{tabular}{|c|c|c|c|c|c|c|}
\hline \multirow[t]{2}{*}{ Parameters } & \multirow{2}{*}{$\begin{array}{l}\text { Treatment } \\
\text { group }\end{array}$} & \multirow{2}{*}{$\begin{array}{l}\text { Covariate } \\
\text { baseline }\end{array}$} & \multicolumn{4}{|c|}{ Adjusted cell means } \\
\hline & & & 6 months & 12 months & 18 months & 24 months \\
\hline \multirow[t]{2}{*}{ Haemoglobin $(\mathrm{g} / \mathrm{dl}) \dagger$} & $\mathrm{ND}^{* *}$ & $13.00(0.43) \div$ & $13 \cdot 47$ & $14 \cdot 14$ & $13 \cdot 78$ & $13 \cdot 85$ \\
\hline & Control & $12 \cdot 88(0 \cdot 32)$ & $12 \cdot 90$ & $12 \cdot 91$ & $12 \cdot 96$ & $12 \cdot 85$ \\
\hline \multirow[t]{2}{*}{ Packed cell volume } & $\mathrm{ND}^{* *}$ & $0.39(0.01)$ & $0 \cdot 41$ & 0.43 & $0 \cdot 43$ & 0.42 \\
\hline & Control & $0.38(0 \cdot 01)$ & $0 \cdot 38$ & $0 \cdot 39$ & $0 \cdot 39$ & $0 \cdot 37$ \\
\hline \multirow{2}{*}{$\begin{array}{l}\text { White blood cell } \\
\text { count } \times 10^{-4} / I\end{array}$} & ND & $8.41(0 \cdot 70)$ & $7 \cdot 61$ & $7 \cdot 94$ & $7 \cdot 77$ & $8 \cdot 87$ \\
\hline & Control & $7.42(0 \cdot 34)$ & $7 \cdot 64$ & $7 \cdot 88$ & $7 \cdot 54$ & $7 \cdot 49$ \\
\hline \multirow[t]{2}{*}{$\operatorname{ESR}(\mathrm{mm} / \mathrm{h})$} & ND & $38 \cdot 8(5 \cdot 1)$ & $26 \cdot 6$ & $24 \cdot 6$ & $27 \cdot 4$ & $31 \cdot 8$ \\
\hline & Control & $36 \cdot 6(5 \cdot 5)$ & $34 \cdot 6$ & $36 \cdot 4$ & $37 \cdot 0$ & $31 \cdot 9$ \\
\hline \multirow{2}{*}{ Serum calcium $(\mathrm{mmol} / \mathrm{l})$} & ND & $2 \cdot 38(0 \cdot 16)$ & $2 \cdot 35$ & $2 \cdot 38$ & $2 \cdot 39$ & $2 \cdot 36$ \\
\hline & Control & $2.38(0 \cdot 02)$ & $2 \cdot 37$ & $2 \cdot 42$ & $2 \cdot 38$ & $2 \cdot 39$ \\
\hline \multirow[t]{2}{*}{ Serum phosphate $(\mathrm{mmol} / \mathrm{l})$} & $\mathrm{ND}^{* *}$ & $1.05(0.04)$ & 0.93 & 0.90 & 0.89 & 0.93 \\
\hline & Control & $1.01(0 \cdot 05)$ & $1 \cdot 06$ & $1 \cdot 14$ & 1.04 & $1 \cdot 03$ \\
\hline \multirow{2}{*}{$\begin{array}{l}\text { Urinary calcium/ } \\
\text { creatinine ratio }\end{array}$} & ND & $0.41(0.08)$ & $0 \cdot 33$ & $0 \cdot 39$ & $0 \cdot 37$ & $0 \cdot 30$ \\
\hline & Control & $0.35(0.04)$ & $0 \cdot 32$ & $0 \cdot 34$ & $0 \cdot 31$ & $0 \cdot 27$ \\
\hline \multirow{2}{*}{$\begin{array}{l}\text { Urinary phosphate/ } \\
\text { creatinine ratio }\end{array}$} & ND & $2 \cdot 49(0 \cdot 19)$ & $2 \cdot 31$ & $2 \cdot 25$ & $2 \cdot 39$ & $2 \cdot 28$ \\
\hline & Control & $2 \cdot 68(0 \cdot 15)$ & $2 \cdot 19$ & $2 \cdot 49$ & $2 \cdot 58$ & $2 \cdot 48$ \\
\hline \multirow{2}{*}{$\begin{array}{l}\text { Urinary hydroxyproline/ } \\
\text { creatinine ratio }\end{array}$} & $\mathrm{ND}^{*}$ & $0.018(0.001)$ & $0 \cdot 014$ & $0 \cdot 016$ & $0 \cdot 012$ & $0 \cdot 011$ \\
\hline & Control & $0.021(0.002)$ & $0 \cdot 017$ & $0 \cdot 018$ & $0 \cdot 014$ & $0 \cdot 019$ \\
\hline \multirow[t]{2}{*}{ Total body calcium (g) } & ND & $611 \cdot 7(31 \cdot 0)$ & $575 \cdot 1$ & $580 \cdot 6$ & $581 \cdot 7$ & $583 \cdot 9$ \\
\hline & Control & $555.8(26.4)$ & $568 \cdot 0$ & $564 \cdot 1$ & $573 \cdot 7$ & $561 \cdot 6$ \\
\hline \multirow[t]{2}{*}{ Total body phosphorus (g) } & ND & $335(11 \cdot 2)$ & $329 \cdot 3$ & $318 \cdot 8$ & $338 \cdot 5$ & $333 \cdot 9$ \\
\hline & Control & $321(14 \cdot 6)$ & $313 \cdot 3$ & $309 \cdot 3$ & $320 \cdot 5$ & $322 \cdot 7$ \\
\hline \multirow[t]{2}{*}{ Bone index/bone width } & ND & $1 \cdot 22(0 \cdot 07)$ & $1 \cdot 22$ & $1 \cdot 23$ & $1 \cdot 21$ & $1 \cdot 22$ \\
\hline & Control & $1.26(0.06)$ & $1 \cdot 23$ & $1 \cdot 21$ & $1 \cdot 19$ & $1 \cdot 22$ \\
\hline \multirow{2}{*}{ Body weight (kg) } & ND & $58 \cdot 3(2 \cdot 6)$ & $56 \cdot 9$ & $56 \cdot 4$ & $55 \cdot 7$ & $54 \cdot 9$ \\
\hline & Control & $53 \cdot 2(2 \cdot 3)$ & $55 \cdot 8$ & $55 \cdot 6$ & $56 \cdot 1$ & $55 \cdot 9$ \\
\hline \multirow[t]{2}{*}{ Total body nitrogen $(\mathrm{g})$} & $\mathrm{ND}^{* *}$ & $1062(55 \cdot 2)$ & $1056 \cdot 5$ & $1 \mathrm{i} 12 \cdot 4$ & $1159 \cdot 6$ & $1147 \cdot 7$ \\
\hline & Control & $952(36 \cdot 0)$ & $932 \cdot 2$ & $947 \cdot 3$ & $975 \cdot 6$ & $949 \cdot 9$ \\
\hline \multirow[t]{2}{*}{ Total body potassium $(\mathrm{g})$} & $\mathrm{ND}^{* *}$ & $1919(78 \cdot 7)$ & $2029 \cdot 0$ & $2140 \cdot 5$ & $2142 \cdot 9$ & $2111 \cdot 8$ \\
\hline & Control & $1726(64 \cdot 4)$ & $1848 \cdot 8$ & $1819 \cdot 4$ & $1863 \cdot 7$ & $1822 \cdot 7$ \\
\hline
\end{tabular}

${ }^{*}$ Significant change with active treatment $(\mathrm{p}<0.05) ;{ }^{* *}$ significant change with active treatment $(\mathrm{p}<0 \cdot 01)$.

† Haemoglobin $\mathrm{g} / \mathrm{dl} \times 10=\mathrm{g} / \mathrm{l}$.

$\ddagger$ Values are mean (SEM).

felt practical to submit any additional patients to neutron activation analysis. Because of this mismatch, when non-parametric statistical methods were used the changes occurring over the study period were used as a basis for comparison of the treatment groups rather than for testing the absolute values for variables at the end of the study. Although the investigators derived an anecdotal impression of the euphoric sense of wellbeing that occurred in some rheumatoid patients treated with nandrolone decanoate, this might have been related to the drug or may be a response to the regular attendance of the nurse who provided the injections.

The most striking finding was of significant improvement in the anaemia of the patients. This occurred only with nandrolone decanoate treatment and might have contributed to the improvement of mood observed in this group. The only other laboratory finding of interest was the decrease in the urinary hydroxyproline/creatinine ratio in the treatment group, perhaps reflecting a decrease in collagen breakdown, though this could also reflect an increase in urinary creatinine in the treatment group.

We found no evidence to suggest that treatment with nandrolone decanoate affected bone metabolism in postmenopausal rheumatoid patients. It should be stressed, however, that total body calcium and bone index measurement did not show any loss of bone in control patients over the two year course of this study. In spite of our careful selection criteria it remains a possibility that the rheumatoid patients under study were not susceptible to osteoporosis. Alternatively, it may be that mineral was lost predominantly from trabecular bone. Both neutron activation and photon absorptiometry measure trabecular and cortical bone together, and neither may be sufficiently sensitive to changes that affect 
only trabecular bone. Because the skeletal changes recorded are much smaller than those required to attain significance, the chances of a type II error arising in this study are remote. In future studies it may be preferable to measure the mineral content of vertebrae, which consist predominantly of trabecular bone, by dual photon absorptiometry, or to measure the trabecular component of long bones by quantitative computed tomography. ${ }^{18}$

Previous studies using single photon absorptiometry had shown that bone mass was lower than normal in patients with arthritic changes. ${ }^{19}$ The opinion was expressed that reduced physical activity rather than the arthritis was the cause of low bone mass. Despite improved wellbeing and significant improvement in total body nitrogen and haemoglobin levels there was no significant improvement in bone mass in the present series, nor was there any significant difference in physical activity between the two groups. In view of the previous findings this would suggest that increased total body nitrogen and haemoglobin levels per se do not lead to any real improvement in the condition. This suggests that other factors, perhaps of a psychological nature, might be more important in achieving better physical activity levels in patients with arthritis.

Our results contrast with those of Reid et al, who also used neutron activation analysis in patients with rheumatoid arthritis treated with and without steroids and found an increased bone loss in corticosteroid treated RA patients that was more likely to be attributable to drug therapy than to disease activity. ${ }^{20}$ Although in our study there was no weight gain in the patients treated with nandrolone decanoate, there was a marked increase in total body nitrogen and potassium. The mean gain in nitrogen was of the order of $100 \mathrm{~g}$, which would correspond with an increase of approximately $3 \mathrm{~kg}$ protein. Since there was no overall weight gain in nandrolone decanoate treated patients, this would suggest that the effect of the steroid is to alter the balance of body composition, increasing the proportion of fat free tissue.

The main side effects were hoarseness and change in voice. This worried the patients more than breast enlargement or the growth of facial hair. Although rheumatoid arthritis can cause involvement of the cricoarytenoid joint, this was not seen in the control group, and we think this more likely to be a direct result of therapy. In view of the risk of laryngeal neoplasm in this age group most patients complaining of hoarseness were referred for specialist ear, nose, and throat examination to exclude neoplasia. No obvious cause for the deepening of the voice was found as a result of this specialist referral.

Although 19-nortestosterone modifies the im- mune system in systemic lupus erythematosus, ${ }^{21}$ and $\frac{\mathrm{D}}{\omega}$ a related anabolic steroid, stanozolol, has been claimed to be successful in rheumatoid arthritis $\stackrel{\vec{\rho}}{\mathscr{\theta}}$ because of its fibrinolytic enhancing properties, ${ }^{22}$ we $\overline{0}$ found no evidence that nandrolone decanoate has any disease modifying action in this study.

We are grateful to Organon laboratories for supplying the drugs and, in particular, the help of Mr D J Nelson, Ms R Campbell, and Dr M I Foreman who assisted with the statistical analysis. We also thank B Oldroyd and D W Krupowicz for the neutron activation measurements, Mrs V Rhind for clinical assessments, and Mrs R Schofield for preparing the script.

\section{References}

1 Maddison P J, Bacon P A. Vitamin D deficiency, spontaneous fractures, and osteopenia in rheumatoid arthritis. $\mathrm{Br}$ Med $\mathrm{J}$ 1974; iv: 433-5.

2 Bird $\mathrm{H} \mathrm{A}$. Bone biopsy in the investigation of bone pain and fractures. Rheumatol Rehabil 1979; 18: 38-42.

3 Kennedy A C, Allam B F, Rooncy P J, et al. Hypercalcaemia in rheumatoid arthritis: investigation of its causes and implications Ann Rheum Dis 1979; 38: 401-2.

4 Bird H A, Peacock M. Storer J H, Wright V. Comparison of scrum $25-\mathrm{OH}$ vitamin $\mathrm{D}$ concentrations in rheumatoid arthritis and ostcoarthrosis. Br Med J 1980; 280: 1416.

5 Bird $\mathrm{H} \mathrm{A}$, Wright $\mathrm{V}$, Hennes U, Theiss E. Comparison of scrum 1,25-dihydroxycholccalciferol concentrations in rheumatoid arthritis and ostcoarthrosis. Ann Rheum Dis 1982; 41: 257-8.

6 Rajapkse C, Thompson R, Grennan D M, et al. Increased bone metabolism in rhcumatoid arthritis as measured by the wholebody retention of "Tc' ${ }^{\text {in }}$ methylenc diphosphonatc. Ann Rheum Dis 1983; 42: 138-41

7 Gribbin H R, Flavell Matts S G. Mode of action and use of anabolic steroids. Br J Clin Pract 1976; 30: 3-9.

8 Chesnut C H III, Nelp W B, Baylink D J, Denney J D. Effect of methandrostenolone on postmenopausal bone wasting as assessed by changes in total bone mineral mass. Metabolism 1977; 26: 267-77.

9 Sharafi A, Pcarson D, Oxby C B, et al. Multi-element analysis of the human body using ncutron activation. Phys Med Biol o 1983; 28: 203-14.

10) West R R, Recd G W. Mcasurement of bone mincral in vivo by photon bcam scanning. Br J Radiol 1970; 43: 886-93.

11 Bjclle A O, Nilsson B E. Ostcoporosis in rhcumatoid arthritis. I Calcif Tissue Res 1970; 5: 327-32.

12 Ropes M W, Bennett G A, Cobb S, Jacox R, Jessar R A. 1958 Revision of diagnostic criteria for rheumatoid arthritis. Arthritis $\mathrm{N}$ Rheum 1959; 2: 16.

13 Ritchic D M, Boylc J A, McInnes J M, et al. Clinical studics with an articular index for the assessment of joint tenderness in paticnts with rhcumatoid arthritis. $Q J$ Med 1968; 37: 393-406.

14 Hancock D H. Radiation absorption analysis of tissuc composition in vivo. Department of Medical Physics, University of Lecds, 1974. (PhD thesis.)

15 Winer B J. Statistical principles in experimental design. New York: McGraw-Hill, 1971.

16 Siegel S. Nonparametric statistics for the behavioural sciences. New York: McGraw-Hill, 1956.

17 Stecl R G. Torric J H. Principles and procedures of statistics. New York: McGraw-Hill, 1980.

18 Wahner H W, Dunn W L, Riggs L. Assessment of bone mineral. J Nucl Med 1984; 25: 1241-53. 
19 Hancock D A, Asiedu-Offei S, Atkinson P J, Reed G W, Wright V. Femoral bone mass in patients with rheumatoid arthritis and osteoarthrosis. Rheumatol Rehabil 1978; 17: 65-71.

20 Reid D M, Kennedy N S, Smith M A, Tothill P, Nuki G. Total body calcium in rheumatoid arthritis: effects of disease activity and corticosteroid treatment. Br Med J 1982; 285: 330-2.
21 Hazelton R A, McCruden A, Stimson W H, Sturrock R D. The effects of 19-nortestosterone treatment on clinical and laboratory parameters in patients with systemic lupus erythematosus. Ann Rheum Dis 1981; 40: 626.

22 Belch J J F, Madhok R, McArdle B, Capell H, Forbes C D, Sturrock R D. Stanozolol as a treatment for rheumatoid arthritis. $B r J$ Rheumatol 1985; 24: 102. 